\title{
Chest wall reconstruction for sarcoma with vertical expandable prosthetic titanium ribs. First reported use in an adult patient
}

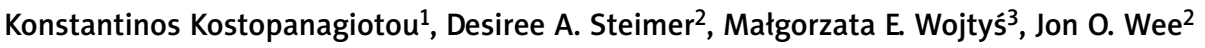 \\ 1Department of Thoracic Surgery, Attikon University Hospital of Athens, Athens, Greece \\ 2Department of Thoracic Surgery, Brigham and Women's Hospital, Boston, Massachusetts, United States \\ ${ }^{3}$ Department of Thoracic Surgery, Pomeranian University Medical School, Szczecin, Poland
}

Kardiochirurgia i Torakochirurgia Polska 2021; 18 (4): 262-264

Resections of chest wall malignancies - primary or metastatic - require extensive experience in reconstruction techniques and often the use of prosthetic materials. Significant osseomuscular defects of the hemithorax may require reconstruction with a combination of prostheses. Targets are: a) clear resection margins and b) restoration of normal thoracic shape and functioning. The variety of prostheses is not excessive in hospitals, so novel materials may be utilized to achieve acceptable results. In order to reconstruct a large defect, we used the vertical expandable prosthetic titanium rib system (trade name: VEPTR II by Depuy Synthes Companies J\&J). It has never been used before in adult patients as it is designed for correction of chest deformities in children and adolescents [1]. Hereinafter we describe our experience with VEPTR.

A 24-year-old man presented with recurrence of a previously resected sarcoma of the right hemithorax (Figures $1 \mathrm{~A}-\mathrm{C}$ ). Extrathoracic metastasis were excluded by positron emission tomography scan. He underwent reoperation with reconstruction in the left lateral decubitus position and double lumen ventilation. An extended posterolateral thoracotomy was performed and the subcutaneous tissues were dissected off meticulously to keep the tumor's capsule intact. The $3^{\text {rd }}$ to $7^{\text {th }}$ ribs were resected and the mass was removed en-bloc with the inferior part of the scapula and part of the right hemi-diaphragm, which were also infiltrated. The complete specimen measured $30 \times 25 \mathrm{~cm}$ and was resected at macroscopic clear margins (Figure $2 \mathrm{~A}$ ). No lung parenchyma was infiltrated. The resulting defect required reconstruction with rigid prosthesis and patch. Two VEPTR-II rods were cut manually and bent in the custom length and shape (Figure $2 \mathrm{~B}$ ). Each bar is composed of two parts fitting one inside the other at mid-length and then anchored around the rib with a ring-type locking mechanism (Figure $1 \mathrm{D}$ ). No securing screws are drilled on the ribs. The $2^{\text {nd }}$ to $8^{\text {th }}$ ribs were bridged vertically with two rods of the VEPTR system. For completion two synthetic non-absorbable patches were secured superficially to the rods with non-absorbable sutures. A previously prepared omental flap filled the space between the synthetic patch and the subcutaneous tissues (Figure $2 \mathrm{C}$ ). The large defect was restored in shape and volume. Finally, two $28 \mathrm{Fr}$ chest drains and a single subcutaneous vacuum drain were inserted (Figure $1 \mathrm{D}$ ). Extubation and postoperative breathing effort were normal. At the second postoperative week a subcutaneous seroma formed, which was aspirated regularly for 3 weeks.

This system was used for the first time in an adult patient. Commonest contemporary chest wall reconstruction systems are titanium bars with screws. In contrast, the VEPTR spinal system was designed for a different use. Primary indications are various childhood thoracic deformities, e.g. early onset spinal scoliosis, but it has also been used in resection of pediatric malignancies [2-4]. Its paraspinal position permits elongation of the bar in its long axis to match the growth rate of children and adolescents. It does not require screws so any dislocations are unlikely. Adequate rigidity is provided by the durable titanium material. Clinically no 'fixed' chest developed as it could possibly occur with Palacos cement and prolene mesh. We based our decision for using VEPTR on: a) the length of vertical bars to bridge the defect effectively; $b$ ) the absence of screws to avoid future dislocation; $c$ ) easy installation and contouring; and d) immediate kit availability. We propose the VEPTR spinal system for adult chest wall resection cases of very large defects as an effective alternative to other prostheses.

\section{Disclosure}

The authors report no conflict of interest.

Address for correspondence: Konstantinos Kostopanagiotou MD, PhD, Department of Thoracic Surgery, Attikon University Hospital of Athens, Athens, Greece, e-mail: kostop@hotmail.co.uk

Received: 30.05.2021, accepted: 5.09.2021. 

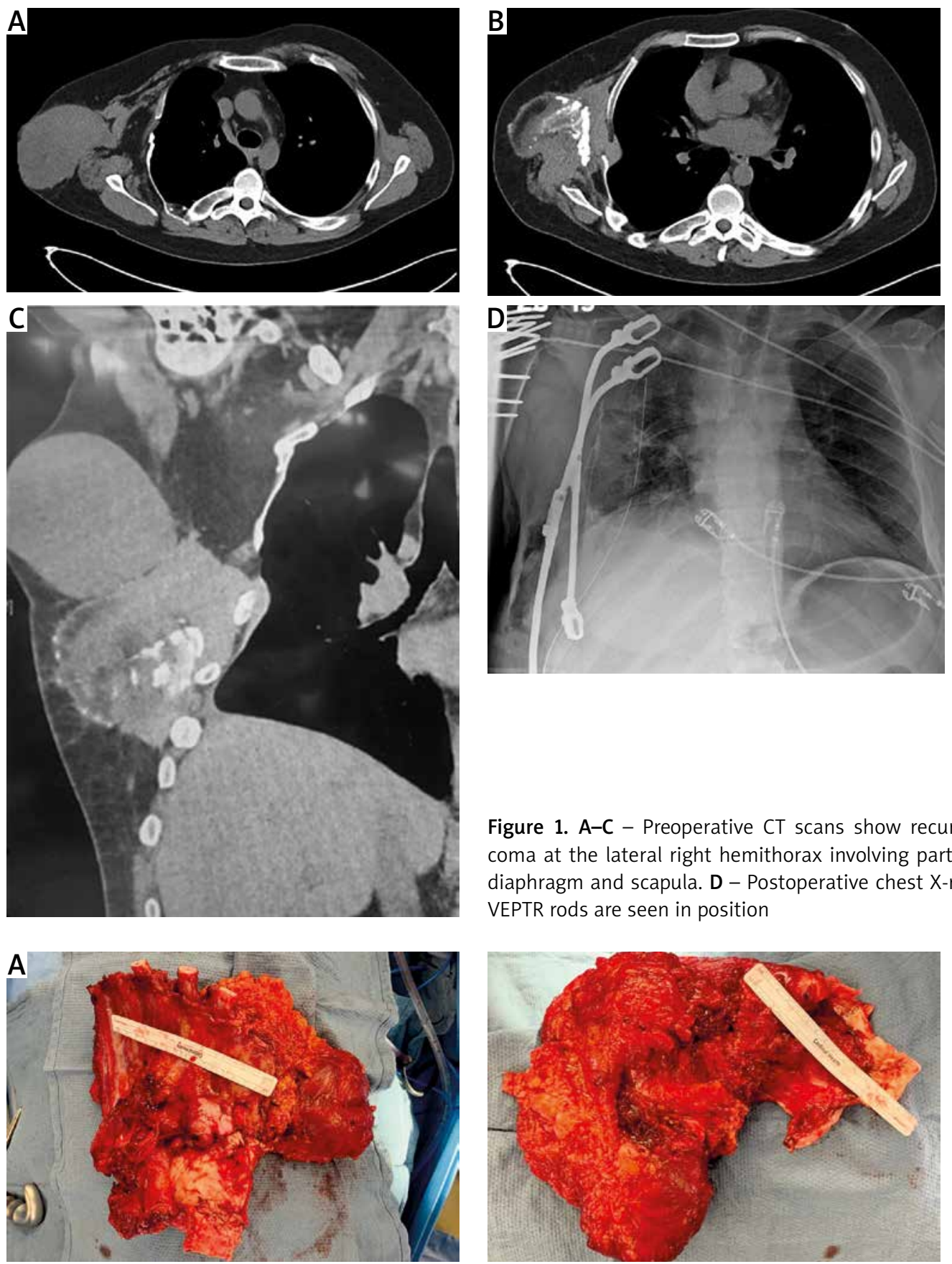

Figure 1. A-C - Preoperative CT scans show recurrence of sarcoma at the lateral right hemithorax involving part of the hemidiaphragm and scapula. D - Postoperative chest X-ray where the VEPTR rods are seen in position
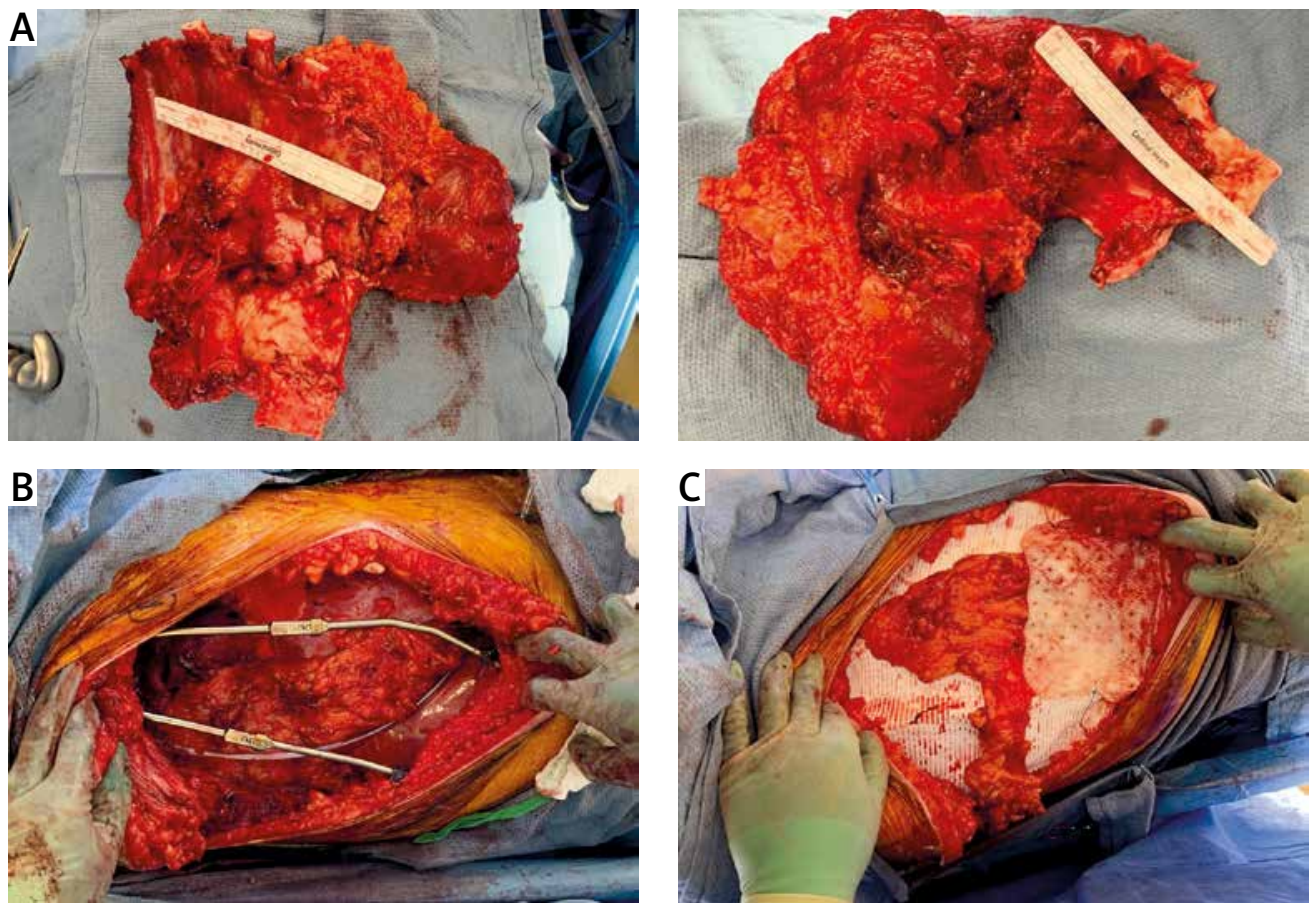

Figure 2. A - En-bloc removal of the specimen results in a significant chest wall defect which requiring reconstruction to allow normal breathing mechanics and body posture. B - Two VEPTR rods bridging vertically the right antero-lateral hemithorax. $\mathbf{C}-$ The reconstruction is completed with two synthetic non-absorbable patches and an omental flap over the rods. These two compartments require separate postoperative draining 


\section{References}

1. Campbell RM Jr. VEPTR: past experience and the future of VEPTR principles. Eur Spine J 2013; Suppl 2: S106-S117.

2. Stephenson JT, Song K, Avansino JR, Mesher A, Waldhausen JH. Novel titanium constructs for chest wall reconstruction in children. J Pediatr Surg 2011; 46: 1005-1010.
3. Gapany C, Raffoul W, Zambelli PY, Joseph JM. Latissimus dorsi muscle-flap over Gore-Tex patch for coverage of large thoracic defects in paediatric Ewing sarcoma. Pediatr Blood Cancer 2009; 52: 679-681.

4. Marqués C, Pizones J, Sánchez-Márquez JM, Martín-Baldan M, Fernández-Baíllo N, Sánchez Pérez-Grueso FJ. Surgical treatment of scoliosis developed after extended chest wall resection due to askin tumor during childhood. Spine Deform 2019; 7: 180-185. 